\title{
Quality of Life among Patients with Type 2 Diabetes Mellitus
}

\author{
Mariamma V George ${ }^{1}$, Dr. Jayarani Premkumar ${ }^{2}$ \\ ${ }^{1}$ Principal, Shri Vinoba Bhave College of Nursing, Silvassa, UT of DNH \\ ${ }^{2}$ Former Nursing Superintendent, Christian Medical College, Vellore, Tamilnadu
}

\begin{abstract}
A Cross sectional survey was conducted to assess the quality of life (QOL) of patients with type 2 diabetes mellitus. The study was conducted in selected government hospitals of Udupi district, Karnataka. Quality of life was assessed by a standardized tool 'Quality of Life Instrument for Indian Diabetes Patients (QOLID). The tool consists of 34 items covering eight domains namely role limitations due physical health, physical endurance, general health, treatment satisfaction, symptom botherness, financial worries, emotional/mental health, and diet satisfaction. Data was collected after obtaining informed consent. QOL was categorized as poor, moderate and good. The finding of the present study showed that most $(49 \%)$ of the subjects had good and $47 \%$ of them had average QOL related to role limitation. Almost $48 \%$ of the subjects had average and $46 \%$ of them had good QOL related to Physical endurance. Majority (63\%) of the subjects had average and $28 \%$ of them had good QOL related to general health and $50 \%$ of the subjects had average QOL and $41 \%$ of them had good QOL related to treatment satisfaction whereas $55 \%$ of them had average and $28 \%$ of them had good QOL related to symptom botherness. Almost $57 \%$ of the subjects had average and $25 \%$ of them had good QOL related to financial worries. Most (59\%) of the subjects had average and $23 \%$ of them had good QOL related to diet satisfaction. Majority (52\%) of the subjects had good QOL and $45 \%$ of them had average QOL related to mental and emotional health. The present study showed overall QOL average in $59 \%$ and good in $41 \%$ of the subjects.
\end{abstract}

Keywords: Quality of Life, Type 2 Diabetes Mellitus

\section{Introduction.}

Globally, an estimated 422 million adults were living with diabetes in 2014, compared to 108 million in 1980. Over the past decade, diabetes prevalence has risen faster in low- and middle-income countries than in high-income countries. Diabetes caused 1.5 million deaths in 2012. Higher-thanoptimal blood glucose caused an additional 2.2 million deaths, by increasing the risks of cardiovascular and other diseases. The percentage of deaths attributable to high blood glucose or diabetes that occurs prior to age 70 is higher in low- and middle-income countries than in high-income countries. When diabetes is not well managed, complications develop that threaten health and endanger life. Acute complications are a significant contributor to mortality, costs and poor quality of life. This diversification of complications and increased years of life spent with diabetes indicates a need to better monitor the quality of life of people with diabetes and assess the impact of interventions on quality of life ${ }^{[1]}$

\section{Statement of the Problem}

A study to assess the Quality of Life among patients with type 2 diabetes mellitus in selected government hospitals of Udupi, Karnataka.

\section{Objectives}

The objective of the study was to assess the quality of life of patients with type 2 diabetes mellitus.

\section{Materials and Methods}

A cross sectional study was conducted among 100 diabetic patients from selected government hospitals of Udupi, Karnataka. Quality of life was assessed by 'Quality of Life Instrument for Indian Diabetes Patients (QOLID). The tool was developed by Jitender Nagpal. et al from Sitaram Bhartia Institute of Science and Research New Delhi. The questionnaire consists of 34 items covering eight domains namely role limitations due physical health, physical endurance, general health, treatment satisfaction, symptom botherness, financial worries, emotional/mental health, and diet satisfaction. For data analysis QOL was categorized as poor, average and good. Data was collected after obtaining informed consent. Data was analyzed using descriptive statistics.

\section{Results}

5.1Distribution of Subjects based on demographic and Clinical Variables

Table 1: Distribution of subjects based on demographic and morbidity variables

\begin{tabular}{|l|r|r|}
\hline \multirow{2}{*}{ Demographic variables } & \multicolumn{2}{|c|}{$\begin{array}{c}\text { Frequency } \\
\text { /Percentage }\end{array}$} \\
\cline { 2 - 3 } & $\mathrm{f}$ & $\%$ \\
\hline Age in years & & \\
\hline $1 . \quad 35-40$ & 3 & 3 \\
\hline $2 . \quad 41-50$ & 24 & 24 \\
\hline $3 . \quad 51-60$ & 27 & 27 \\
\hline $4 . \quad 61-70$ & 42 & 42 \\
\hline $5 . \quad>70$ & 4 & 4 \\
\hline Gender & & \\
\hline $1 . \quad$ Male & 58 & 48 \\
\hline 2. Female & & 52 \\
\hline
\end{tabular}

Volume 6 Issue 12, December 2017 
International Journal of Science and Research (IJSR)

ISSN (Online): 2319-7064

Index Copernicus Value (2016): 79.57 | Impact Factor (2015): 6.391

\begin{tabular}{|c|c|c|}
\hline \multicolumn{3}{|l|}{ Marital status } \\
\hline 1.Married & 88 & 88 \\
\hline 2.Widow/ Widower & 12 & 12 \\
\hline \multicolumn{3}{|l|}{ Religion } \\
\hline 1. Hindu & 84 & 84 \\
\hline 2. Muslim & 8 & 8 \\
\hline 3. Christian & 8 & 8 \\
\hline \multicolumn{3}{|l|}{ Educational status } \\
\hline 1.Primary & 2 & 2 \\
\hline 2. Secondary & 40 & 40 \\
\hline 3. High School & 20 & 20 \\
\hline 4. Pre University & 30 & 30 \\
\hline 5. Graduate & 3 & 3 \\
\hline 6. $\quad$ Post graduate & 5 & 5 \\
\hline \multicolumn{3}{|l|}{ Occupational status } \\
\hline 1. Unemployed & 19 & 19 \\
\hline 2. Unskilled & 41 & 41 \\
\hline 3. $\quad$ Semiskilled & 29 & 29 \\
\hline 4. $\quad$ Skilled & 3 & 3 \\
\hline 5. Shop/ farm owner & 1 & 1 \\
\hline 6. Semi professional & 7 & 7 \\
\hline \multicolumn{3}{|l|}{ Monthly income in rupees } \\
\hline 1. $>5001$ & 21 & 21 \\
\hline 2. $4001-5000$ & 15 & 15 \\
\hline 3. $3001-4000$ & 25 & 25 \\
\hline $\begin{array}{ll}4 . \quad 2001-3000 \\
\end{array}$ & 26 & 26 \\
\hline 5. $<2000$ & 13 & 13 \\
\hline \multicolumn{3}{|l|}{ Duration of diabetes in years } \\
\hline 1. Less than 5 years & 54 & 54 \\
\hline 2. 5-10 years & 37 & 37 \\
\hline 3. $11-15$ years & 6 & 6 \\
\hline 4. Above 15 years & 3 & 3 \\
\hline \multicolumn{3}{|l|}{ Treatment } \\
\hline Oral hypoglycemic agents & 98 & 98 \\
\hline Oral hypoglycemic agents and Insulin & 2 & 2 \\
\hline \multicolumn{3}{|l|}{ Body Mass Index } \\
\hline Normal: $18.5-24.99$ & 44 & 44 \\
\hline Overweight: $25-29.99$ & 46 & 46 \\
\hline Obese : above 30 & 10 & 10 \\
\hline
\end{tabular}

\begin{tabular}{|c|c|c|c|c|c|}
\hline Emotional/Mental Health & 10 & 25 & 18.56 & 3.06 & 19.00 \\
\hline Diet satisfaction & 3 & 15 & 9.66 & 2.53 & 9.50 \\
\hline Overall QOL & 81 & 166 & 119.65 & 15.31 & 122.50 \\
\hline
\end{tabular}

The data presented in table no:2 shows that mean QOL with regard to Symptom botherness was $9.97 \pm 2.54$ whereas mean QOL related to general health was $10.21 \pm 2.24$ and the mean score of Total QOL was 119.65 15.31 .

\subsection{Distribution of Subjects based on Domains of QOL.}

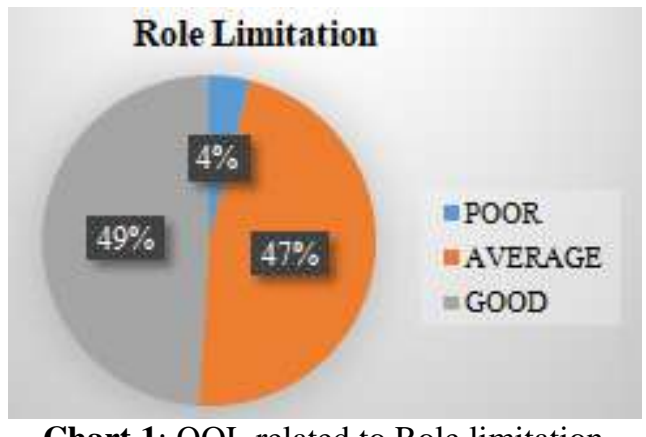

Chart 1: QOL related to Role limitation

The data presented in the above chart reveals that most (49\%) of the subjects had good QOL whereas $47 \%$ of them had average QOL related to role limitation.

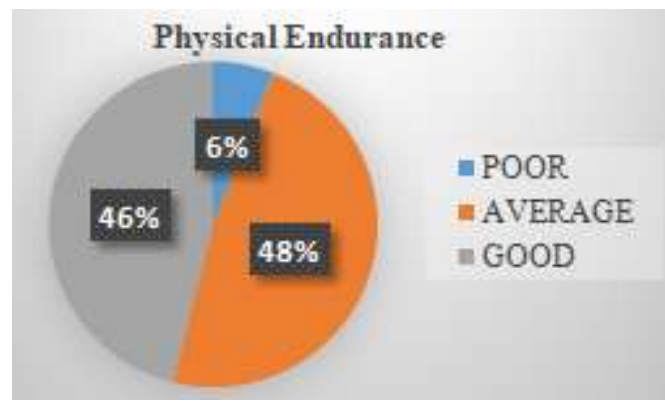

Chart 2: QOL related to Physical Endurance

The data presented in table no: 1 shows that most (42\%) of the subjects belonged to the age group of 61 to 70 years and 27 of them were between 51 to 60 years. Most $(52 \%)$ of them were male by gender and $88 \%$ of the subjects were married and living with their spouse. Majority (84\%) of them were Hindu by religion. Most (40\%) of them were with secondary education, and $41 \%$ of them were unskilled workers. Most (54\%) of them were with duration of illness less than 5 year's duration. Majority (98\%) of the subjects were on oral hypoglycemic agents and most $(46 \%)$ of them were overweight with body mass index between 25-29.9

\subsection{Distribution of Subjects based on Mean, Median and SD on Domains of QOL.}

Table 2: Mean Median and standard deviation of QOL.

\begin{tabular}{|c|c|c|c|c|c|}
\hline \multicolumn{7}{c}{$\mathrm{N}=100$} \\
\hline $\begin{array}{c}\text { Domains of QOL } \\
\text { Rcore }\end{array}$ & $\begin{array}{c}\text { Max } \\
\text { Score }\end{array}$ & Mean & SD & Median \\
\hline physical health & 10 & 30 & 22.56 & 4.76 & 22.00 \\
\hline Physical Endurance & 11 & 30 & 21.87 & 4.56 & 22.00 \\
\hline General health & 5 & 15 & 10.21 & 2.24 & 10.00 \\
\hline Treatment Satisfaction & 5 & 20 & 14.62 & 3.06 & 15.00 \\
\hline Symptom botherness & 4 & 15 & 9.97 & 2.54 & 10.00 \\
\hline Financial Worries & 7 & 19 & 12.20 & 2.63 & 12.00 \\
\hline
\end{tabular}

The data presented in the above chart reveals that most (48\%) of the subjects had average QOL whereas $46 \%$ of them had good QOL related to Physical endurance

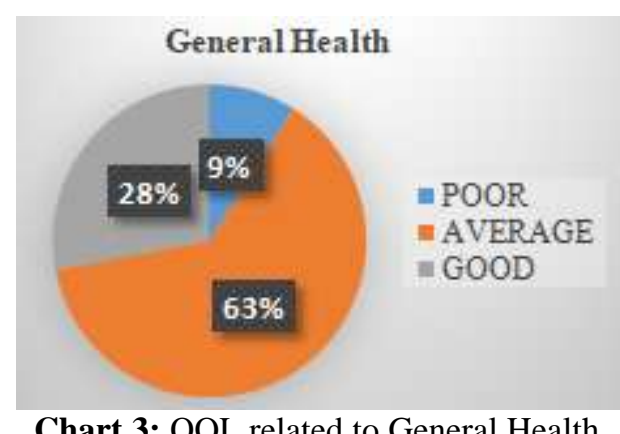

The data presented in the above chart reveals that majority $(63 \%)$ of the subjects had average QOL whereas $28 \%$ of them had good QOL related to general health.

\section{Volume 6 Issue 12, December 2017}




\section{International Journal of Science and Research (IJSR) \\ ISSN (Online): 2319-7064}

Index Copernicus Value (2016): 79.57 | Impact Factor (2015): 6.391

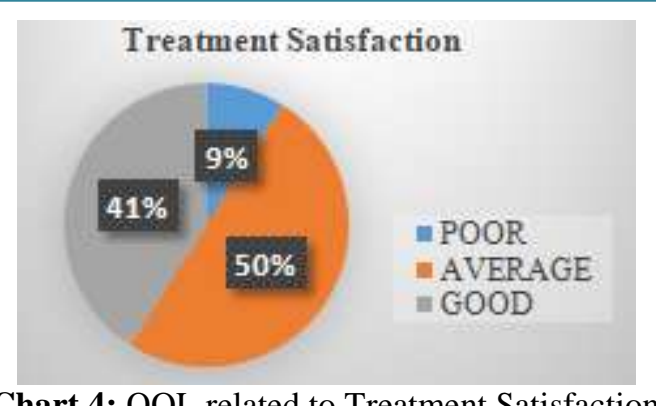

Chart 4: QOL related to Treatment Satisfaction

The data presented in the above chart reveals that most (50\%) of the subjects had average QOL whereas $41 \%$ of them had good QOL related to treatment satisfaction.

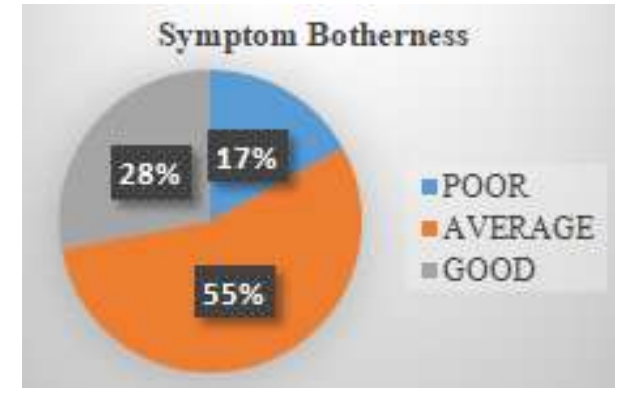

Chart 5: QOL related to Symptom Botherness

The data presented in the above chart reveals that most (55\%) of the subjects had average QOL whereas $28 \%$ of them had good QOL related to symptom botherness

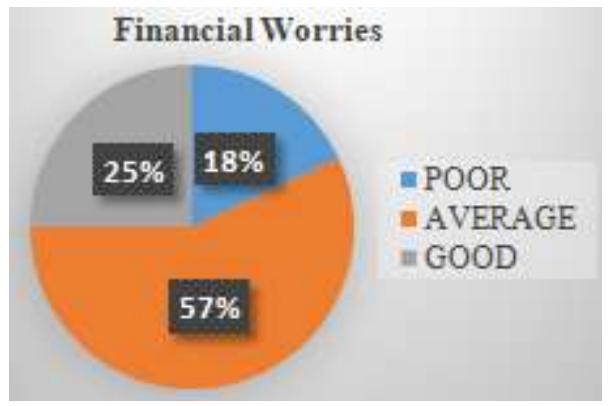

Chart 6: QOL related to Financial Worries

The data presented in the above chart reveals that most (57\%) of the subjects had average QOL whereas $25 \%$ of them had good QOL related to Financial worries.

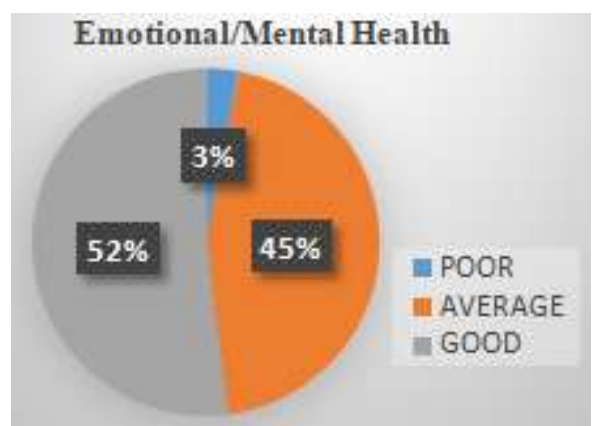

Chart 7: QOL related to Emotional/ Mental Health

The data presented in the above chart reveals that most (52\%) of the subjects had good QOL whereas $45 \%$ of them had average QOL related to mental and emotional health.

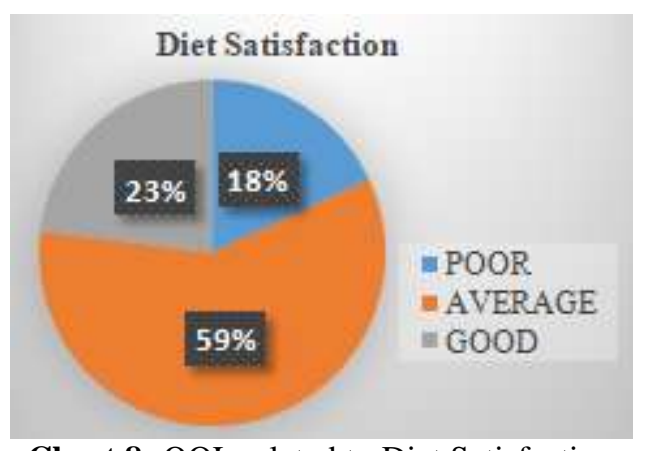

Chart 8: QOL related to Diet Satisfaction

The data presented in the above chart reveals that most (59\%) of the subjects had average QOL whereas $23 \%$ of them had good QOL related to diet satisfaction.

\subsection{Distribution of Subjects based on Overall QOL}

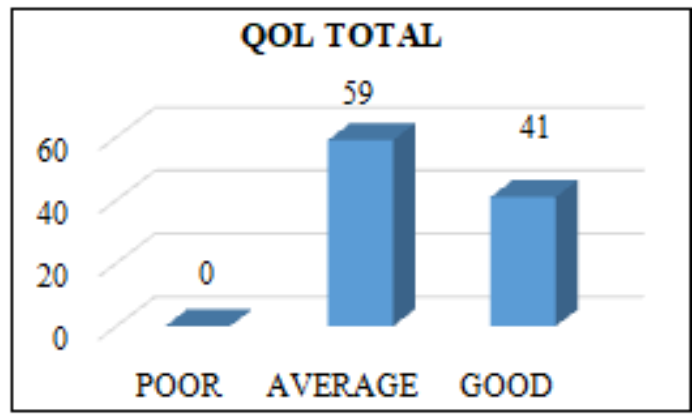

Chart 8: Overall QOL

The data presented in the above chart reveals that overall QOL was average in $59 \%$ and good in $41 \%$ of the subjects.

\section{Discussion}

In the present study most (49\%) of the subjects had good and $47 \%$ of them had average QOL related to role limitation. Almost $48 \%$ of the subjects had average and $46 \%$ of them had good QOL related to Physical endurance. Majority $(63 \%)$ of the subjects had average and $28 \%$ of them had good QOL related to general health. Similar findings were reported in a study in Sydney in which over a third of the subjects were with impeded mobility, $48.5 \%$ struggled with personal care and hygiene, $74 \%$ experienced difficulties at work, $80 \%$ of those incapacitated while attempting to do household chores and more than $75 \%$ experienced pain and discomfort. ${ }^{[2]}$ A study conducted in Mysore, Karnataka also reported Poor Physical QoL score in 57\% of the diabetic patients. ${ }^{[3]}$ Another study conducted in Patna also reported $28.2 \%$ of the subjects being unsatisfied with their general health. ${ }^{[4]}$

In the present study most (50\%) of the subjects had average QOL and $41 \%$ of them had good QOL related to treatment satisfaction and $55 \%$ of them had average and $28 \%$ of them had good QOL related to symptom botherness. Almost 57\% of the subjects had average and $25 \%$ of them had good QOL related to financial worries. Most (59\%) of the subjects had average and $23 \%$ of them had good QOL related to diet satisfaction. Similar findings were reported in a study conducted in Shivamogga, Karnataka where $61 \%$ of were "moderately satisfied" with, both, the current treatment for

Volume 6 Issue 12, December 2017 


\section{International Journal of Science and Research (IJSR) \\ ISSN (Online): 2319-7064}

Index Copernicus Value (2016): 79.57 | Impact Factor (2015): 6.391

diabetes, as well as the time it takes for management of their diabetes and for regular check-ups. Almost 32\% of the patients reported thirst or dry mouth "very frequently" and nearly $60 \%$ of them experienced frequent urination "very frequently" while $32 \%$ of them perceived the cost involved in management of their diabetes to be "not at all expensive" and $20 \%$ as "very expensive". QOL related to diet satisfaction was reported by $52 \%$ of the patients that they have no choice at all while eating meals or snacks away from home and $29 \%$ of them always felt a restriction in choosing the foods while they were eating outdoors. Almost $50 \%$ of them were "moderately satisfied" and $43 \%$ of them were "very satisfied" with themselves and personal relationships ${ }^{[5]}$

In the present study most (52\%) of the subjects had good QOL and $45 \%$ of them had average QOL related to mental and emotional health. A Study conducted in Sydney reported $73.5 \%$ bouts of anxiety and depression due to diabetes. ${ }^{[2]}$ Similar findings were also reported in a study conducted in Shivamogga where $45 \%$ of them were "moderately satisfied" with the emotional support received from their friends and family. ${ }^{[5]} \mathrm{A}$ longitudinal study also reported similar findings where reduction in times spent with friends and family, contacts by telephone and attendance at social clubs or religious groups. ${ }^{[6]}$

The present study showed overall QOL average in 59\% and good in $41 \%$ of the subjects. A longitudinal study also reported fivefold increase in the odds of a subject reporting quality of life had become significantly poorer. ${ }^{[6]}$ A study conducted in Patna also reported average QOL in 56.5\% and good only in $32.9 \%$ of diabetic cases. ${ }^{[4]}$ Similar findings were reported in another study where $25 \%$ reported good quality of life whereas $48 \%$ rated their quality of life as poor $^{[7]}$

\section{Recommendations}

7.1 Interventions aimed at diabetes self management will help to improve quality of life in type 2 diabetes mellitus patients.

7.2 Case based management helps to individualize priorities for patients which in turn will help to improve their quality of life

\section{Conclusion}

Diabetes is chronic disorder that affects the quality of life of patients. The findings of the present study suggest that diabetes significantly affects quality of life of patients. Achieving glycemic control through medications, diet, exercise and early identification and prevention of complications is essential in the management of diabetes mellitus. Diabetes and its complications bring about substantial economic loss to people with diabetes and their families and to health systems and national economies through direct medical costs and loss of work and wages. Improving the QOL of patients with diabetes remains a major task for health professionals.

\section{References}

[1] WHO. Global report on Diabetes http:// who.int/diabetes/global-report/en/ 2016

[2] Mustapha W, Hossain ZS, Loughlin KO. Management and Impact of Diabetes on Quality of Life among the Lebanese Community of Sydney: A Quantitative Study. Diabetes and Metabolism.2014. 5: 329. doi:10.4172/2155-6156.1000329

[3] Savitha Rani B B, Ashok N C, Kulkarni P, Renuka M. Does glycemic status influence quality of life of type II diabetes patients: an exploratory study in Mysuru, Karnataka, India. International Journal of Community Medicine and Public Health | January 2017. Vol 4. Issue 1. p-59-61.

[4] Kumar P, Agarwal N , Singh C M , Pandey S, Ranjan A , Kumar D. Diabetes and quality of life - a pilot study. International Journal of Medical Science and Public Health . 2016 . Vol 5., Issue 06. pp1143-1147

[5] Kumar P, Krishna M. Quality of Life in Diabetes Mellitus Science Journal of Public Health 2015; 3(3): 310-313

[6] Feng X, Astell-Burt T. Impact of a type 2 diabetes diagnosis on mental health, quality of life, and social contacts: a longitudinal study. BMJ Open Diabetes Research and Care 2017; 5:e000198. doi: 10.1136 /bmj drc-2016-000198.

[7] Khongsdir S, George C E, Mukherjee D, Norman. Quality of Life in Patients with Diabetes and Hypertension in Karnataka- An Observational Study International Journal of Medical and Health Sciences Jan 2015,Vol-4; Issue-1; p-98102.

Volume 6 Issue 12, December 2017

www.ijsr.net

Licensed Under Creative Commons Attribution CC BY 